\title{
Staphylococcus spp.: importantes riscos à saúde pública
}

\section{Renata Resende Prado ${ }^{1}$, Eduardo Almeida Freitas ${ }^{1}$, Edson Campos Valadares Júnior ${ }^{1}$, Priscila Cristina Costa ${ }^{1}$, Mariana Cristina Siqueira ${ }^{1}$, Daise Aparecida Rossi ${ }^{1,2}$}

${ }^{1}$ Laboratório de Biotecnologia Animal Aplicada.

${ }^{2}$ Programa de Pós-Graduação em Ciências Veterinárias

* para correspondência, E-mail: renatarprado@yahoo.com.br

RESUMO. O Staphylococcus spp. são cocos gram-positivos da família Microccaceae, anaeróbicos facultativos, imóveis, não produtores de esporos e catalase positiva com ampla distribuição. É um dos agentes mais comuns responsáveis por surtos de intoxicação alimentar, por serem normalmente transmitidos aos alimentos. A intoxicação é decorrente da ingestão de enterotoxinas pré-formadas no alimento contaminado pela bactéria, a qual pode continuar viável ou não. As manifestações por estes agentes podem levar à doenças que são ocasionadas pela ação destes microrganismos patogênicos ou por sua toxina. Muitos são os sintomas, que podem facilmente ser confundidos com intoxicações alimentares de outros microrganismos. Por isso faz-se necessário um estudo mais abrangente de sua epidemiologia e das formas de contágio através dos alimentos.

Palavras chave: Staphylococcus, saúde pública, patogenia

\section{Staphylococcus spp.: important public health hazards}

\begin{abstract}
Staphylococcus spp. are gram-positive cocci of Microccaceae family, facultative anaerobic, real estate, don't produce spores and catalase positive with wide distribution. It is one of the most common agents responsible for outbreaks of food poisoning, because they are usually transmitted to food. The poisoning is caused by ingestion of preformed enterotoxin in food contaminated by the bacterium, which can remain viable or not. Demonstrations by these agents can lead to diseases that are caused by the action of these pathogenic microorganisms or their toxina. There are many symptoms that can easily be confused with food poisoning from other microorganisms. Therefore it is necessary a more comprehensive study of the epidemiology and the forms of infection through food.
\end{abstract}

Keywords: Staphylococcus, health Public, pathogenesis

\section{Introdução}

Amplamente distribuídos no ambiente, os Staphylococcus fazem parte da microbiota normal da pele e mucosas de pessoas sadias. Porém, com importante relevância na cavidade nasal como armazenadora e disseminadora de Staphylococcus patogênicos, podendo ser encontradas frequentemente no ar, em fezes, esgotos e alimentos. O Staphylococcus spp é um dos agentes mais comuns responsáveis por surtos de intoxicação alimentar, por serem normalmente transmitidos aos alimentos por meio de manipuladores, portadores assintomáticos, e por meio dos animais como o gado leiteiro. As manifestações por estes agentes podem levar à doenças que são ocasionadas pela ação destes microrganismos patogênicos ou por sua toxina. Vários tipos de alimentos são incriminados epidemiologicamente e são frequentemente relatados como capazes de suportar o desenvolvimento natural e artificial de Staphylococcus aureus, bem como a produção de suas enterotoxinas. Dentre os alimentos podem ser destacados os produtos lácteos: queijos, leite cru, pasteurizado e em pó, manteiga e sorvete; produtos de confeitaria: tortas, bolos recheados e doces cremosos como também carnes frescas e curadas, ovos e massas alimentícias. As características celulares das bactérias são amplas, sendo microrganismos mesófilos com temperatura de crescimento entre 7 e $47,8^{\circ} \mathrm{C}$ e podem produzir enterotoxinas termo resistentes a temperaturas entre 10 e $46^{\circ} \mathrm{C} . \mathrm{O} \mathrm{pH}$ ideal para 
seu desenvolvimento varia entre 7 a 7,5, mas é possível a multiplicação em alimentos com $\mathrm{pH}$ variando entre 4,2 e 9,3. Sendo assim, possível sua destruição por tratamento térmico, mas suas enterotoxina permanecem ativas nos alimentos, consideradas termoestáveis, sendo um risco em potencial para a saúde pública.

\section{Aspectos epidemiológicos}

A segurança alimentar é de fato, de grande importância para a manutenção da saúde pública e apesar de práticas e sistemas de monitoramento avançados, as doenças veiculadas por alimentos ou surtos de doenças transmitidas por alimentos continuam a ser comuns (Thakur et al., 2009).

As doenças de origem alimentar causadas pela ingestão de alimentos contaminados por agentes microbianos e/ou toxinas representam considerável risco para milhões de pessoas, conforme as descrições da Organização das Nações Unidas da Agricultura e Alimentação (FAO) e Organização Mundial de Saúde (WHO). As enfermidades de origem alimentar, não causam somente transtornos à saúde e ao bem estar dos indivíduos afetados, mas também se associam a graves consequências econômicas para a sociedade.

Uma das intoxicações alimentares mais frequentes é causada pelos microrganismos Staphylococcus aureus. É decorrente da ingestão de enterotoxinas pré-formadas no alimento contaminado pela bactéria, a qual pode continuar viável ou não (Teixeira et al., 2008). As intoxicações produzidas pela ingestão de suas enterotoxinas estão geralmente veiculadas ao consumo de leite ou dos seus derivados, como queijos não processados, cremes e molhos (Barreto el al., 1998).

O homem e os animais são os principais reservatórios de $S$.aureus, sendo a cavidade nasal do homem seu principal habitat (Franco; Landgraf, 2005; Wong; Bergdoll, 2002) e pode ser encontrado em $30 \%$ a $50 \%$ dos indivíduos saudáveis (Loir et al., 2009; Wong; Bergdolll, 2002; U.S. Food and drug administration, 1992; Brewer, 1991). É a partir da cavidade nasal que o microrganismo atinge a epiderme, ar, água, solo, alimentos, ou qualquer outro objeto que entre em contato com o indivíduo.

$\mathrm{Na}$ qual os alimentos que requerem considerável manipulação para seu preparo, que permanecem em temperatura ambiente elevada e por longo tempo após sua preparação são, geralmente, considerados de alto risco. Segundo Roberts (1990), os quadros de intoxicação por $S$. aureus estão associados a comidas frias muito manipuladas durante a preparação e produtos lácteos, especialmente aqueles preparados a partir de leite cru.

Vários são os relatos de intoxicação por S.aureus. Nos Estados Unidos os casos de surtos alimentares a enterotoxina estafilocócica é comumente isolada, sendo relatados anualmente em média 185.000 casos (Mustafa et al., 2009).

$\mathrm{Na}$ Inglaterra e país de Gales, entre 1992 e 1993, 204 alimentos foram envolvidos em surtos, sendo o leite e derivados associados a 4,4\% destes e, na Alemanha 1993 e 1996, do total de 547 casos, 5,5\% tiveram o leite e seus derivados como responsáveis por casos de intoxicação alimentar (Buyser et al., 2001). Na França, por exemplo, o principal alimento envolvido nos quadros de intoxicação por estafilococos entre 1999 e 2000 foram os derivados lácteos, principalmente os queijos, sendo responsáveis por 32\% dos casos (Loir et al., 2003).

No Brasil, esta estatística apresentou uma relevância maior pois, estudo realizado no estado da Paraíba demonstrou dados da vigilância epidemiológica do estado e revelam que o agente etiológico veiculado em $50 \%$ dos casos de queijos contaminados foi o Staphylococcus aureus (Ruwer et al., 2011).

Em municípios de Minas Gerais, de 127 amostras de cepas de $S$. aureus isoladas de casos de mastites, 60 (47\%) delas produziram pelo menos um dos tipos de enterotoxinas testadas (TSST-1, EEA, EEB, EEC e EEE), sendo algumas cepas produtoras de até quatro delas (Cardoso et al., 2000).

A prevalência em relação aos surtos envolvidos por intoxicação pela ingestão de toxina estafilocócica variam nos diversos países e em diferentes regiões de um mesmo país, devido às diferenças nos hábitos alimentares.

O S. aureus é um dos principais agentes causadores de infecções na glândula mamária de vacas produtoras de leite (Cenci-Goga, 2003; Wong; Ergdoll, 2002), sendo considerado o microrganismo patogênico mais frequentemente isolado de leite cru (Zecconi; Hahn, 2001) e em quadros de mastite (Silva et al., 2000). De acordo com a WHO (1995) este microrganismo é o maior responsável pelo aumento na Contagem de Células Somáticas (CCS) no leite, o que acarreta 
redução na produtividade e comprometimento na composição nutricional do leite (Asperger, 1994).

\section{Características gerais e patogênicas}

Pertencentes da família Microccaceae, os Staphylococcus são cocos gram-positivos com aproximadamente 0,5 a $1,5 \mu \mathrm{c}$ de diâmetro, anaeróbios facultativos, imóveis, não produtores de esporos e catalase positivo. Podem se apresentar em diversas formas, que vão desde isolados, aos pares, em cadeias curtas ou agrupados irregularmente com aspecto semelhante a cacho de uva (Santos et al., 2007), classificados como microrganismos mesófilos, apresentando crescimento entre 7 e $47,8{ }^{\circ} \mathrm{C}$ e podem produzir enterotoxinas termo resistentes a temperaturas entre 10 e $46^{\circ} \mathrm{C}$, com temperatura ótima entre 40 e $45^{\circ} \mathrm{C}$. $\mathrm{O}$ pH ideal para seu desenvolvimento varia entre 7 a 7,5, mas é possível a multiplicação em alimentos com $\mathrm{pH}$ variando entre 4,2 e 9,3. Crescem em concentrações de até $15 \%$ de $\mathrm{NaCl}$, sendo considerados como microrganismos halofílicos (Santos et al., 2007).

O gênero Staphylococcus encontra-se dividido em dois grupos, os estafilococos coagulase negativos que estão subdivido em mais de 10 espécies e os estafilococos coagulase positivos que foram subdivididos em 4 espécies: $S$. aureus, $S$. intermedius, $S$. hycuse $S$. delphinie que podem ser diferenciados com base na fermentação de carboidratos com formação de ácido, redução de nitrato a nitrito, presença de termonucleases, coagulase, produção de pigmentos, acetoína e hemólise (Carmo, 2001). Alguns fatores de virulência dos estafilococos, como a coagulase e a termonuclease (Tnase) são associados à sua capacidade enterotoxigênica, estão como os indicadores mais aceitos quanto à presuntiva evidência da sua propriedade enterotoxigênica (Pereira et al., 2000).

A produção da coagulase, uma enzima extracelular, é uma das provas mais amplamente utilizadas para correlacionar a cepa isolada com a produção de enterotoxina (EE), embora a relação entre a produção da coagulase e a de EE não seja absoluta (Wong \& Bergdoll, 2002). A coagulase promove a transformação do fibrinogênio em fibrina e consequente coagulação do plasma sanguíneo (Wong \& Bergdoll, 2002; PEREIRAet al., 2000). Já a termonuclease é uma proteína de forma globular, com cadeia polipeptídica simples, que apresenta estabilidade térmica, produzida somente pelos estafilococos coagulase positivo (Carmo, 2001).

A maioria dos surtos de intoxicação alimentar está relacionados à contaminação de alimentos por $S$. aureus enterotoxigênicos. As enterotoxinas estafilocócica são os principais agentes de intoxicação de origem bacteriana no homem e tem sido relatadas em váriossurtos de doenças transmissíveis por alimentos (Lamaite et al., 2005).

As enterotoxinas estafilocócicas são proteínas básicas de baixo peso molecular (26.000.-34.000 DA) resistentes a ação de enzimas proteolíticas (Carmo, 2001), pertencem a uma família de toxinas pirogênicas produzidas tanto por bactéria do gênero Staphylococcus como Streptococcus (Fagundes \& Oliveira, 2004), Atualmente foram identificadas dezoito tipos distintos de enterotoxinas (Borges et al., 2008). A temperatura para produção de enterotoxina estafilocócica é de $37^{\circ} \mathrm{C}$, podendo ser produzida a 25 e $30^{\circ} \mathrm{C}$, porem em quantidades menores do que a $37^{\circ} \mathrm{C}$ (Carmo, 2001).

Várias são as condições necessárias para que ocorra produção de enterotoxina nos alimentos, dentre as principais que o alimento forneça condições para o crescimento bacteriano, como temperatura e teor de água satisfatório, e que as cepas presentes tenham característica enterotoxigênica.

A produção de enterotoxinas é influenciada pela temperatura, $\mathrm{pH}$, aw, tamanho do inóculo, fonte de carbono e nitrogênio, concentração de sal e condições atmosféricas do substrato. Em temperaturas ótimas, a enterotoxina torna-se detectável entre 4 a 6 horas (Franco \& Landgraf, 2005; Wong \& Ergdolll, 2002). Por isso os alimentos expostos a temperaturas mais elevadas apresentam um maior potencial à produção de enterotoxinas pelos estafilococos, em especial alimentos fermentados e lácteos.

A maioria das intoxicações é produzida principalmente pela ingestão de EEA e EED (Zoli et al., 2002), sendo necessário também uma quantidade menor de microorganismos para a sua produção, quando comparadas aos outros tipos de EEs (Wong \& Bergdoll, 2002; Zoli et al., 2002). Segundo Kokan \& Bergdoll (1987), as cepas produtoras de EED são responsáveis pela maior parte dos surtos de intoxicação estafilocócica, principalmente aqueles onde $\mathrm{o}$ alimento envolvido é o leite. Nos casos de mastite 
estafilocócica, a enterotoxina mais frequentemente produzida é a EEC (Wilson et al., 1991). Mas recentemente foram descritos outros tipos de EEs (EEG a EEJ) em casos de mastite, resultados estes ainda não bem esclarecidos (Katsuda et al., 2005).

\section{Sinais clínicos}

Os sintomas comumente observados na maioria dos casos de gastroenterite estafilocócica inclui náuseas, vômitos, cólicas abdominais, diarréias, sudorese e cefaléia, podendo variar com o grau de susceptibilidade da pessoa e com a concentração da enterotoxina ingerida, sendo necessária cerca de 106 de células por grama de alimento para que a toxina seja acumulada em níveis capazes de provocar intoxicação alimentar (Rodrigues et al., 2004), tendo já sido relatado intoxicações em níveis menores de célula por grama de alimento.

O período de incubação pode variar de 30 minutos a 6 horas, sendo que na maioria dos casos aparecem de 2 a 4 horas (Carmo et al., 2001). Geralmente esta intoxicação não é letal, com uma duração dos sintomas entre 1 a 3 dias, tendo casos que podem evoluir para quadros mais graves (Fagundes \& Oliveira, 2004).Segundo trabalho realizado por Evenson et al. (1988) foi possível inferir que a quantidade mínima de enterotoxina estafilocócica para causar sintomatologia em humanos é de 100 a 200 ng.

\section{Tratamento e medidas de controle}

O diagnóstico da intoxicação estafilocócica é feito basicamente por dois aspectos: sintomatologia e presença da enterotoxina (EE) no alimento (Najera-Sanches et al., 2003).

As intoxicações alimentares causadas por Staphylococcus spp. apresentam implicações importantes para a saúde pública, visto que as toxinas estafilocócicas são excretadas e permanecem viáveis nos alimentos que são destinados ao consumo. Torna-se importante a prevenção e o controle higiênico na produção de alimentos, seja ele doméstico, artesanal ou industrial, visando melhorar qualidade do alimento. Os alimentos por se tratarem de um importante elo na cadeia epidemiológica de doenças transmissíveis se tornam fundamental sua observação e conservação em condições adequadas para não favorecer a multiplicação de microrganismos que podem vir a causar alterações e/ou produzirem sintomas de intoxicação alimentar aos consumidores (Stamford et al., 2006). As células bacterianas dos Staphylococcus spp.podem ser destruídas por tratamento térmico, mas suas enterotoxinas permanecem ativas nos alimentos, por isso consideradas termoestáveis, sendo um risco em potencial para a saúde pública (Carmo, 1997).

\section{Referências Bibliográficas}

Asperger, H. Staphylococcus aureus. In: International Dairy Federation. Group of Experts A10/11. The significance of pathogenic microorganisms in raw milk. Brussels: IDF, 1994. p.24-42. (SpecialIssue, 9405).

Barreto, S.M. \& Lima e Costa, M.F. 1998. Investigação de um surto de intoxicação alimentar em Belo Horizonte, Brasil. Caderno de Saúde Pública, 14, 442-443.

Borges, M.F., Nassu, R.,T., Pereira, J.L., Andrade, A.P.C., Kuaye, A.Y. Perfil de contaminação PR Staphylococcus e suas enterotoxinas e monitoriazação das condições de higiene em uma linha de produção de queijo coalho. Rev. de Ciência rural. 38, 2008.

Buyser, M.L. Dufour, B., Maire, M., Lafarge, V. Implication of milk and milk products in food-borne diseases in France and in different industrialized countries. International Journal of Food Microbiology, 67, 1-17, 2001.

Cardoso, H.F.T, Carmo, L.S. \& Silva, N. 2000. Detecção da toxina 1 da síndrome do choque tóxico em amostras de $S$. aureus isoladas de mastite bovina. Arquivo Brasileiro de Medicina Veterinária e Zootecnia, 52, 7-10.

Carmo, L.S., Dias, R.S. \& Linardi, V.R. 2002. Food poisoning due to enterotoxigenic strains of Staphylococcus present in Minas Chesse and raw milk in Brasil. Food Microbiol, 19, 914.

Cenci-Goga, B.T., Karama, M., Rossito, P.V., Morgante, R.A. \& Cullor, J.S. 2003. Enterotoxin production by Staphylococcus aureusisolated from mastitic cows. Journal of Food Protection, 66, 1693-1696.

Center For Diseases Control (Us). 2009. Food Safety. Disponível em: <http:/www.cdc.gov/briefing/fncidod/eid/voln 05/mead.htm>. Acesso em: 23 mar. 2009. 
Fagundes, H. \& Oliveira, C.A.F. 2004. Infecções intramamárias causadas por Staphylococcus aureus e suas implicações em saúde pública. Revista Ciência Rural, 34, 1315-1320.

Fao/Who, Food And Agriculture Organization Of The Unites nations/ World Health Organization. Codex Alimentarus - Food Hygiene Basic Texts, $3^{\mathrm{a}}$ ed, 65. p, 2003.

Franco, B.D.G.M. \& Landgraf, M. Microbiologia dos alimentos. São Paulo: Editora Atheneu, 2005.

Katsuda, K., Hata, E. \& Eguchi, M. 2005. Molecular typing of S.aureus isolated from bovine mastitic milk on the basic of toxin genes and coagulase gene polymorphisms. Veterinary Microbiology, 105, 301-305.

Kokan, N.P. \& Bergdoll, M.S. 1987. Detection of low enterotoxina producing Staphylococcus aureus strains. Appliedand Environmental Microbiology, 53, 2675-2676.

Lamaita, H.C., Cerqueira, M.M.O.P., Carmo, L.S., Santos, D.A., Penna, C.F.A.M. \& Souza, M.R. Contagem de Staphylococcus sp. e detecção de enterotoxinas estafilocócicas etoxina da síndrome do choque tóxico em amostra de leite cru refrigerados. Arquivo Brasileiro de Medicina Veterinária e Zootecnia. 57, 702-709.

Lancette, G.A., Tatini, S.R. Staphylococcus aureus. In: Vandrzant, C. (Ed.). Compendium of methods for the microbiological examination of foods. 3.ed. Washington: American Public Health Association, 1992.

Loir, Y. Le, Baron, F. \& Gautir, M. 2003. Staphylococcus aureus and food poisoning. Genetic Molecular Research, 2, 63-76.

Mustafa, M.M.S., Jain, L.C.S. \& Agrawal, C.V.K. 2009. Food Poisoning Outbreak in a Military Establishment. MJAFI, 65, 240-243.

Pereira, M.A., Pereira, J.L., Serrano, A.M. \& Bergdoll, M.S. 2000. Estafilococos: Até onde sua importância em alimentos? Higiene Alimentar, 14, 32-39.

Roberts, D. 1990. Sources of infection: foods. The Lancet, 336, 859-861.

Ruwer, C.M., Moura, J.F. \& Gonçalves, M.J.F. Surtos de doenças transmitidas por alimentos em Manaus, Amazonas (2005-2009): o problema do queijo coalho. 2011. Segurança alimentar e nutricional, 18, 60-66.
Santos, A.L., Santos, D.O., Freitas, C.C., Ferreira, B.L.A., Afonso, I.F., Rodrigues, C.R. \& Castro, H.C. 2007. Staphylococcus aureus: visitando uma cepa de importância hospitalar. Jornal brasileiro de patologia medica laboratorial. 43, 413-423

Stamford, T.L.M., Silva, C.G.M., Mota, R.A., Neto, A.C. 2006. Enterotoxidade de Staphylococcus spp. isolados de leite in natura. Revista de Ciência e Tecnologia de Alimentos, 26, 41-45.

Thakur, M., Olafsson, S., Lee, J.S. \& Hurburg, C.R. 2010. Data mining for recognizing patterns in food borne disease outbreaks. Journal of Food Engineering, 97, 213-227.

Safety and Applied Nutrition. Bacterial Pathogens Growth and Inactivation. In: Fish and fisheries products hazards and controls guidance. 3.ed. jun. 2001. Disponível em: $<$ http://seafood.ucdavis.edu/haccp/compendiu m/chapt19.htm>. Acesso em: 10 mai. 2005.

Wilson, I.G., Cooper, J.E. \& Gilmour, A. 1991. Detection of enterotoxigenic Staphylococcus aureus in dried skimmed milk: use of the polymerase chain reaction for amplification and detection of staphylococcal enterotoxina genes ent $\mathrm{B}$ and ent $\mathrm{C} 1$ and the thermonuclease gene nunc. Applied and Environmental Microbiology, 57, 1793-1798.

Wong, A.C.L., Bergdoll, M.S. Staphylococcal food poisoning. In: Cliver, DO; Riemann, H.P. Foodborne Diseases. 2.ed. Amsterdam: Academic Press, 2002. p. 231-248.

World Health Organization. Emerging and other communicable diseases, surveillance and control: Report of a WHO consultation of public health implications of consumption of raw milk and meat and their products, Germany, 17-20, December, 1995. (WHO/EMC/ZOO/96.7). Disponível em: <www.who.int/hq/1996/WHO_emc_zoo96.7. pdf $>$. Acessoem: 3 set. 2005.

Zecconi, A. \& Hahn, G. 2001. Staphylococcus aureus in raw milk and human health risk. Bulletinof IDF, Brussels, 345, 15-18.

Zoli, J.A., Negrete, I.R.A. \& Oliveira, T.C.R.M. 2002. Avaliação da contaminação por Staphylococcus aureus e Salmonella spp. de maionese de batata comercializada em Londrina, PR. Higiene Alimentar, 16, 62-70, 2002. 
Recebido em Agosto 4, 2014

Aceito em Setembro 23, 2014

License information: This is an open-access article distributed under the terms of the Creative
Commons Attribution License, which permits unrestricted use, distribution, and reproduction in any medium, provided the original work is properly cited. 